\title{
Clinical presentation and investigation of patients proceeding to isotope lung scanning for suspected pulmonary embolism
}

\author{
A.G. Fennerty, H.G.M. Shetty, D. Paton, G. Roberts, P.A. Routledge and \\ I.A. Campbell
}

Departments of Thoracic and General Medicine, Radiology and Clinical Pharmacology, Llandough Hospital, Penarth, South Glamorgan CF6 2 YA, UK.

Summary: The presenting features of 250 consecutive patients who underwent a ventilation/perfusion lung scan for suspected pulmonary embolus (PE) were analysed. Ninety-six patients had lung scans highly suggestive of PE, with one or more unmatched segmental perfusion defects (scan positive), 86 had low probability scans (scan negative) and 68 an indeterminate scan.

Scan positive patients were more likely to have $\mathrm{PaO}_{2}$ of less than $10.7 \mathrm{kPa}$, an elevated $P(\mathrm{~A}-\mathrm{a}) \mathrm{O}_{2}$ and an abnormal chest $\mathrm{X}$-ray compared with scan negative patients but these measurements were of poor specificity. Furthermore, scan-positive patients had a higher incidence of lung disease. Localized chest wall tenderness was more common in scan-positive patients, occurring in $9 \%$ of patients, but there were no other significant differences in individual symptoms, signs or electrocardiographic findings between scan-positive and scan-negative patients.

The diagnosis of PE should not be made on clinical grounds alone and all patients suspected of having a PE should at least undergo isotope lung scanning.

\section{Introduction}

A number of studies have suggested that the clinical criteria for diagnosing pulmonary emboli (PE) are non-specific, as demonstrated by the fact that a high proportion of angiographic studies in patients suspected of having a PE are shown to be normal. ${ }^{1.2}$ In the United Kingdom the diagnosis of PE is frequently made on clinical evidence only, ${ }^{3}$ and when objective evidence is sought patients undergo isotope lung scanning rather than angiography. The aim of this study was to compare the presenting features of patients suspected of PE on clinical grounds where the diagnosis was subsequently confirmed or refuted by lung scanning to see whether any features could usefully discriminate between the two groups or be helpful in the management of those patients with indeterminate scans.

\section{Patients and methods}

The case notes of 250 consecutive patients with suspected PE were studied retrospectively. Mean

Correspondence: A.G. Fennerty, M.D., M.R.C.P., The Chest Clinic, Southern General Hospital, 1345 Govan Road, Glasgow G51 4TF, UK.

Accepted: 23 November 1989. age was 53 years (range 18-95), 127 were male. The ventilation/perfusion lung scans were performed between 1983 and 1987 and reviewed by a radiologist and a physician together with the concurrent chest X-ray. Ventilation imaging used $300 \mathrm{mBq}$ of ${ }^{133} \mathrm{Xe}$ with posterior views taken by a scintillation camera with an all purpose low-energy collimator. Perfusion imaging used $70 \mathrm{mBq}{ }^{99} \mathrm{Tc}$ MAA with anterior, posterior and right and left anterior oblique views. Scans were graded according to the findings of Biello et al. ${ }^{4}$ : a high probability scan (scan-positive) showed one or more unmatched segmental perfusion defects with no matching chest $\mathrm{X}$-ray abnormality. A low probability (scan-negative) scan showed a normal perfusion phase, unmatched perfusion defects less than $25 \%$ of a segment, matched areas of ventilation and perfusion defects of less than $75 \%$ of a segment or perfusion defects substantially smaller than an $\mathrm{X}$-ray abnormality. All other scans were classed as indeterminate.

Case notes were studied and the presenting symptoms, signs, concurrent disease, recognized - risk factors, such as recent surgery, immobilization, oral contraceptive, carcinoma, obesity, varicose veins, previous thromboembolic disease, together with chest X-ray findings, electrocardiogram (ECG) and blood gas measurements were recorded for each patient. If signs, symptoms or 
risk factors were not commented on they were assumed to be absent. Statistical analysis was performed by the chi-squared test, $P<0.05$ being taken as the minimal level of statistical significance.

\section{Results}

On review of the lung scans, 96 patients were judged to have a high probability scan, 86 negative scans and 68 indeterminate scans. Details of each group, with presenting symptoms, signs, co-existing disease, risk factors and results of chest X-ray, ECG and blood gases are given in Tables I-IV.

Patients with indeterminate scans were more likely to complain of dyspnoea than patients with positive or negative scans $(P<0.01)$ otherwise there were no significant differences in the individual presenting symptoms between the three groups (Table II). Local chest wall tenderness occurred in 9 scan-positive patients compared with one scannegative patient $(P<0.02)$, otherwise there was no significant difference in presenting signs, ECG findings, or risk factors between scan-positive and scan-negative patients (Tables II, III and IV). Five patients had multiple, segmental perfusion defects but only one of these was hypotensive. ECG changes suggestive of $P E$ (right ventricular strain, right bundle branch block, right axis deviation, ' $P$ ' pulmonale) occurred in $9 \%$ of both scan-positive and scan-negative patients. The S1Q3T3 configuration was seen in 2 scan-positive and 3 scannegative subjects. Compared with scan-negative patients, scan-positive patients were more likely to have an abnormal chest $\mathrm{X}$-ray $(70 \%$ versus $50 \%$; $P<0.01)$ and a higher incidence of lung disease $(25 \%$ versus $9 \% ; P<0.001)$. Patients with an indeterminate scan were more likely to have associated disease, particularly cardiorespiratory disease compared with the other two groups $(P<0.01)$. Thirty per cent of scan-positive patients had no associated disease or recognized risk factor (Tables III and IV). There was no significant difference in the presenting symptoms, signs or investigations between patients presenting with symptoms lasting more or less than 10 days prior to lung scanning in either of the 3 groups.

Only a small number of patients in each group had blood gas measurements performed. More scan-positive and indeterminate scan patients had a $\mathrm{PaO}_{2}$ of less than $10.7 \mathrm{kPa}, 78 \%(11 / 14)$ and $67 \%$ $(8 / 12)$ respectively compared with scan-negative patients, $36 \%(5 / 14)(P<0.05)$. Similarly, a higher percentage of scan-positive and indeterminate scan patients had alveolar arterial oxygen gradients greater than $2.6 \mathrm{kPa} ; 93 \%$ (13/14) and $92 \%(11 / 12)$ respectively compared with $57 \%(9 / 14)$ of scannegative patients $(P<0.05)$. There was no significant difference in the proportion of subjects
Table I Details of patients grouped according to lung scan results

\begin{tabular}{lccc}
\hline & $\begin{array}{c}\text { Scan- } \\
\text { positive }\end{array}$ & $\begin{array}{c}\text { Scan- } \\
\text { negative }\end{array}$ & $\begin{array}{c}\text { Indeter- } \\
\text { minate } \\
\text { scan }\end{array}$ \\
\hline Number & 96 & 86 & 68 \\
Males & 56 & 35 & 36 \\
Females & 40 & 51 & 32 \\
Mean age (range) & 55 & 51 & 50 \\
& $(18-84)$ & $(23-95)$ & $(27-80)$ \\
Median duration of & 5 & 5 & 7 \\
symptoms in days & $(1-20)$ & $(0-365)$ & $(0-180)$ \\
(range) & & & \\
\hline & & &
\end{tabular}

Table II Presenting symptoms and signs of patients suspected of PE

\begin{tabular}{|c|c|c|c|}
\hline & $\begin{array}{c}\text { Scan- } \\
\text { positive } \\
n=96\end{array}$ & $\begin{array}{c}\text { Scan- } \\
\text { negative } \\
n=86\end{array}$ & $\begin{array}{c}\text { Indeter- } \\
\text { minate } \\
\text { scan } \\
n=68\end{array}$ \\
\hline \multicolumn{4}{|l|}{ Symptoms } \\
\hline Pain - pleuritic & 61 & 59 & 50 \\
\hline non - pleuritic & 16 & 20 & 18 \\
\hline Dyspnoea & $54^{* *}$ & $45^{* *}$ & 75 \\
\hline Cough & 29 & 23 & 35 \\
\hline Haemoptysis & 23 & 13 & 26 \\
\hline Sweats & 17 & 16 & 13 \\
\hline Syncope & 4 & 5 & 0 \\
\hline Abdominal pain & 4 & 2 & 0 \\
\hline Local tenderness & 9 & $1.6^{*}$ & $0^{*}$ \\
\hline Angina & 6 & 1.6 & 3 \\
\hline $\begin{array}{l}\text { Pain, dyspnoea and } \\
\text { haemoptysis }\end{array}$ & 13.5 & 6 & 14.7 \\
\hline \multicolumn{4}{|l|}{ Signs } \\
\hline $\begin{array}{c}\text { Tachycardia }(>100 \\
\text { beats } / \mathrm{min})\end{array}$ & 21 & 19 & 31 \\
\hline $\begin{array}{l}\text { Raised jugular venous } \\
\text { pressure }\end{array}$ & 5 & 5 & 7 \\
\hline Pleural rub & 9 & 9 & 9 \\
\hline Cyanosis & 3 & 1 & 4 \\
\hline Crackles & 28 & 17 & 38 \\
\hline Wheeze & 5 & 2 & 6 \\
\hline $\begin{array}{l}\text { Systolic blood pressure } \\
(<100 \mathrm{mmHg})\end{array}$ & 3 & 0 & 2 \\
\hline Syncope & 3 & 5 & 0 \\
\hline
\end{tabular}

Figures in percent.

${ }^{*} P<0.02$ compared with scan-positive patients. $* * P<0.01$ compared with indeterminate scan patients.

in each group with a $\mathrm{PCO}_{2}$ of less than $4.7 \mathrm{kPa}$.

After a mean (s.d.) follow up period of 42 (11) months, none of the scan-negative patients had suffered a clinical recurrence of PE. Fourteen patients had died of well documented causes or with severe underlying disease which could account for their death, and 14 further patients had received some form of outpatient anticoagulation therapy 
despite a negative scan: this group had no features to distinguish them from the rest of the scannegative group.

Table III Results of preliminary investigations

\begin{tabular}{lccc}
\hline & $\begin{array}{c}\text { Scan- } \\
\text { positive } \\
n=96\end{array}$ & $\begin{array}{c}\text { Scan- } \\
\text { negative } \\
n=86\end{array}$ & $\begin{array}{c}\text { Indeter- } \\
\text { minate } \\
\text { scan } \\
n=68\end{array}$ \\
\hline $\begin{array}{l}\text { Chest } X \text {-ray } \\
\text { Normal }\end{array}$ & 30 & 50 & 13 \\
Abnormal & $70^{* *}$ & 50 & $87^{* *}$ \\
ECG & $n=74$ & $n=69$ & $n=56$ \\
Normal & 68 & 56 & 48 \\
Abnormal & 32 & 44 & 52 \\
Blood gases & $n=14$ & $n=14$ & $n=12$ \\
PaO $2<10.7 \mathrm{kPa}$ & $78^{*}$ & 36 & $67^{*}$ \\
PaCO $2<4.7 \mathrm{kPa}$ & 57 & 64 & 75 \\
$P(\mathrm{~A}-\mathrm{a}) \mathrm{O}_{2}<2.7 \mathrm{kPa}$ & $93^{*}$ & 57 & $92^{*}$ \\
\hline
\end{tabular}

Figures in percent.

${ }^{*} P<0.05{ }^{* *} P<0.01$ compared with scan-negative patients.

Table IV Associated diseases, risk factors and current smoking history of patients suspected of PE

\begin{tabular}{|c|c|c|c|}
\hline & $\begin{array}{c}\text { Scan- } \\
\text { positive } \\
(n=96)\end{array}$ & $\begin{array}{c}\text { Scan- } \\
\text { negative } \\
(n=86)\end{array}$ & $\begin{array}{c}\text { Indeter- } \\
\text { minate } \\
\text { scan } \\
(n=68)\end{array}$ \\
\hline \multicolumn{4}{|l|}{ Associated disease } \\
\hline None & $43^{* *}$ & $48^{* *}$ & 14 \\
\hline Pulmonary & $25^{* * *}$ & 9 & $41^{* * *}$ \\
\hline Cardiovascular & $26 * *$ & $27^{* *}$ & 41 \\
\hline Cerebrovascular & 2 & 1 & 3 \\
\hline Neurological & 2 & $i$ & 3 \\
\hline Connective tissue & 3 & 5 & 1 \\
\hline Haematological & 1 & 0 & 1 \\
\hline Renal & 1 & 0 & 0 \\
\hline Endocrine & 1 & 0 & 1 \\
\hline Metabolic & 1 & 0 & 1 \\
\hline Gastrointestinal & 1 & 0 & 1 \\
\hline Others & 1 & 0 & 0 \\
\hline \multicolumn{4}{|l|}{ Risk factors } \\
\hline Recent surgery & 25 & 15 & 19 \\
\hline Immobilization & 7 & 1 & 7 \\
\hline Obesity & 8 & 5 & 9 \\
\hline Varicose veins & 8 & 2 & 0 \\
\hline Contraceptive pill & 1 & 7 & 4 \\
\hline Carcinoma & 4 & 12 & 6 \\
\hline $\begin{array}{l}\text { Previous thrombo- } \\
\text { embolism }\end{array}$ & 14 & 14 & 3 \\
\hline Current smokers & $43^{*}$ & 58 & $40^{*}$ \\
\hline
\end{tabular}

Figures in percent. ${ }^{*} P<0.05{ }^{* * *} P<0.001$ compared with scan-negative patients. ${ }^{* *} P<0.01$ compared with indeterminate scan patients.

\section{Discussion}

Patients with one or more unmatched segmental defects on ventilation/perfusion lung scan have an $85 \%$ or more likelihood of having a PE demonstrable on angiography ${ }^{4.5}$ and for management purposes may be considered to have PE without the need for further investigation. A low probability scan is generally considered sufficient to rule out the diagnosis of $\mathrm{PE}$ with a less then $7 \%$ probability of a PE demonstrable on angiography ${ }^{4}$ and followup studies have shown no evidence of subsequent PE in these patients. ${ }^{6.7}$ The fact that there was no clinical recurrence of a PE in 72 scan-negative patients left untreated in our study supports the scan diagnosis in this group. Thus the ventilation/ perfusion scan is sufficiently reliable to discriminate between those who are highly likely or unlikely to have suffered a PE.

The presenting symptoms of our scan-positive patients were similar to those in two large studies of patients with angiographically diagnosed PEs. ${ }^{1.5}$ We found no significant difference in the occurrence of individual symptoms between scanpositive and scan-negative patients and even the classic symptoms complex of pleuritic chest pain, dyspnoea and haemoptysis was uncommon in scan-positive patients (13.6\%) and also occurred in $6 \%$ of scan-negative patients. Hull, in a prospective study, found that less than a third of patients presenting with pleuritic chest pain had a PE confirmed by angiography ${ }^{8}$ and in this study only $24 \%$ of patients with this symptom had a positive scan.

Physical signs could not be used to discriminate between scan-positive and -negative patients. Notably, a pleural rub was rarely heard, but when it was, it occurred with the same frequency in both groups of patients. Localized chest wall tenderness has previously been described in patients with $P E^{8}$ and was more common in the scan-positive group although only 9 such patients had this sign. When present, localized tenderness often gave rise to an initial diagnosis of musculoskeletal pain. Five subjects in our series had multiple segmental perfusion defects and may be considered to have suffered a massive PE; only one of them, however, had evidence of circulatory compromise. Similarly in the large study by Bell et al., ${ }^{1}$ where two thirds of the patients had occlusion of $60 \%$ or more of the pulmonary circulation, only $7 \%$ presented in shock. Thus it would seem that clinically it is rarely possible to assess the size of a pulmonary embolus.

The chest X-ray was more likely to be abnormal in scan-positive patients, with areas of consolidation, atelectasis and effusions being the most common abnormalities seen. An abnormal chest $\mathrm{X}$-ray in the right clinical setting might be a useful discriminatory factor, but X-ray changes are no- 
toriously non-specific ${ }^{9}$ and nearly half of the scan negative patients also had abnormal chest $\mathrm{X}$-rays. Reduced vascular markings were seen in only 2 scan-positive patients (one noted retrospectively) and the classical wedge-shaped infarct was not seen in any of the scan-positive patients.

A previous retrospective study has shown that $76 \%$ of patients with a proven $\mathrm{PE}$ have a $\mathrm{PO}_{2}$ of less than $10.7 \mathrm{kPa} .{ }^{10}$ Only a relatively small number of patients in our series underwent blood gas monitoring, but a significantly higher proportion of scanpositive patients had a low $\mathrm{PO}_{2}$ compared with that of scan-negative patients ( $78 \%$ versus $36 \%)$. In an attempt to improve the sensitivity of blood gas measurements in patients with PE Cvitanic et al..$^{10}$ looked at $P_{C O}$ and $P(A-a) O_{2}$. The combination of a low $\mathrm{PO}_{2}$ and a low $\mathrm{PCO}_{2}$, less than $4.7 \mathrm{kPa}$, occurred in $93 \%$ of $\mathrm{PE}$ patients, while a high $P(\mathrm{~A}-\mathrm{a}) \mathrm{O}_{2}$ occurred in $95 \%$ of PE patients. It was thus suggested that these measurements would serve as useful screening tests. In our study, a low $\mathrm{PO}_{2}$ and $\mathrm{PCO}_{2}$ occurred in $93 \%$ of scan-positive patients and $71 \%$ of scan-negative patients. A high $P(\mathrm{~A}-\mathrm{a}) \mathrm{O}_{2}$, using an upper limit of normal of $2.7 \mathrm{kPa}$, which would be an over-estimate for many young patients, occurred in $93 \%$ and $57 \%$ of patients respectively. Thus, while combinations of $P_{2}, P_{2} O_{2}$ and $P(A-a) O_{2}$ may frequently be abnormal in patients with $P E$ their poor specificity appears to make them unhelpful as screening tests when deciding who should proceed to lung scanning. Blood gas measurements in the indeterminate scan group were essentially similar to those of the scan-positive group, partly the result, perhaps, of the high incidence of cardiopulmonary disease in these patients.

It is of interest that the incidence of recognized risk factors was no higher in scan-positive than in scan-negative patients. The interpretation of this finding should be tempered by the fact that our study was confined to those who had ventilation/ perfusion scanning. It is possible that patients who had had surgery or were on the contraceptive pill may have been diagnosed and treated for PE without ventilation/perfusion scanning. Smoking did not seem to be a risk factor for PE with

\section{References}

1. Bell, W.R., Simon, T.L. \& De Mets, O.L. The clinical features of submassive and massive pulmonary emboli. Am J Med 1977, 62: $355-360$.

2. Robin, E.D. Overdiagnosis and overtreatment of pulmonary embolism: The Emperor may have no clothes. Ann Intern Med 1977, 87: 775-781.

3. Prentice, A.G., Lowe, G.D.O. \& Forbes, C.D. Diagnosis and treatment of venous thromboembolism by Consultants in Scotland. Br Med J 1982, 286: 698-699.

4. Biello, D.R., Mattar. A.G.. McKnight, R.C. \& Siegel, B.A Ventilation-perfusions studies in suspected pulmonary embolism. $A J R$ 1979. 133: $1033-1037$. significantly more scan-negative than scan-positive patients having smoked at sometime. Interestingly, an inverse relationship between the development of a post-operative deep venous thrombosis and the number of cigarettes smoked has previously been described. ${ }^{11}$

The difficulty of interpreting ventilation/perfusion scans in the presence of cardiopulmonary disease might account, at least in part, for the much higher incidence of established cardiopulmonary disease noted in the patients in the indeterminate scan group. This group of patients has a $20-40 \%$ probability of having a PE on angiography ${ }^{5}$ and it is these patients, who frequently have poor cardiac reserve, who tend to have a bad prognosis following PE. ${ }^{12} \mathrm{~A}$ case has been made for performing angiography in patients with indeterminate scans. ${ }^{13}$ Accurate interpretation of a pulmonary angiogram depends on regular exposure to the technique, and such experience is rarely available in most district general hospitals, where, despite its low morbidity, this investigation is rarely performed. In practice then, patients are treated on merit. Short course therapy, that is 4 weeks, which has a good risk benefit profile, is probably adequate for many patients ${ }^{14}$ and should perhaps lower the threshold for anti-coagulation in this group. When longer term therapy is indicated after repeated PEs or persistence of risk factors or when the patient is at excessive risk of haemorrhage, referral to a centre with experience in angiography may be appropriate

In the UK it is probable that two thirds of patients suspected of a PE do not go on to have objective investigations, ${ }^{3}$ yet this study shows that clinical features and preliminary investigations cannot distinguish between patients highly likely or unlikely to have had a PE. All patients then, suspected of having a PE, should have a lung scan before embarking on long term anti-coagulant therapy with its attendant risks. Patients with indeterminate scans present a real problem, but our policy is to have a low threshold for treatment and use short course therapy. There remains an important group of patients for whom pulmonary angiography is appropriate.

5. Hull, R.D., Hirsh, J., Carter, C.J. et al. Diagnostic value of ventilation perfusion scanning in patients with suspected pulmonary embolism. Chest 1985, 88: 819-828.

6. Kipper, M.S., Moser, K.M., Kortman, K.E. \& Ashburn, W.L. Long-term follow-up of patients with suspected pulmonary embolism on a normal lung scan. Chest 1982, 82: 411-415.

7. Kahn, D., Bushnell, D.D., Dean. R. \& Perkman, S.B. Clinical outcome of patients with a low probability of pulmonary embolism on ventilation-perfusion lung scan. Arch Intern Med 1989, 149: 377-379. 
8. Hull, R.D., Raskob, G.E., Carter, C.J. et al. Pulmonary embolism in outpatients with pleuritic chest pain. Arch Intern Med 1988, 148: 838-844.

9. Greenspan, R.H., Ravin, C.E., Polonsky, S.M. \& McLoud, T.C. Accuracy of the chest radiograph in diagnosis of pulmonary embolism. Invest Radiol 1982, 17: 539-543.

10. Cvitanic, O. \& Marino, P.C. Improved use of arterial blood gas analysis in suspected pulmonary embolus. Chest 1989, 95: 48-51.

11. Prescott, R.J., Jones, D.R., Vasilescu, C., Henderson, S.T. \& Rucley, C.V. Smoking and risk factors in deep vein thrombosis. Thromb Haemost 1978, 40: 128-133.
12. Paraskos, J.A., Adelstein, S.J., Smith, R.E. et al. Late prognosis of acute pulmonary embolism. N Engl J Med 1973 , 289: 55-58.

13. Windebank, W.J. Diagnosing pulmonary thromboembolism. Br Med J 1987, 294: 1369.

14. Fennerty, A., Campbell, I.A. \& Routledge, P.A. Anticoagulants in venous thromboembolism. Br Med J 1988, 297: 1285-1288. 